\title{
The iron uptake mechanisms of enteropathogenic Escherichia coli: the use of haem and haemoglobin during growth in an iron-limited environment
}

\author{
D. LAW*, K. M. WILKIE†, R. FREEMAN and F. K. GOULD
}

\begin{abstract}
Department of Microbiology, Freeman Hospital, Freeman Road, Newcastle upon Tyne, NE7 7DN and † Department of Biology, Sunderland Polytechnic, Sunderland
\end{abstract}

\begin{abstract}
Summary. The iron uptake mechanisms of enteropathogenic Escherichia coli (EPEC) were examined and compared with those of control $E$. coli strains. The incidence of aerobactin production was similar (39\% and $37 \%$ respectively) in the two groups. The quantities of enterochelin produced by aerobactin-negative EPEC and control strains were similar, as were the quantities of enterochelin produced by aerobactin-positive EPEC and control strains. The ability to use haem or haemoglobin as an iron source in an iron-restricted environment was found in $80.4 \%$ and $60.8 \%$ of EPEC strains respectively, and in $76.6 \%$ and $56.6 \%$ of control $E$. coli strains. The ability of $E$. coli strains to use these compounds was not related to the production of enterochelin or aerobactin or to the production of haemolysins, and may be an important characteristic of bowel organisms. When growing in an iron-limited environment, the iron contained in haemoglobin was used in preference to ovotransferrin-bound iron. During periods of haemoglobin-stimulated growth, the enterochelin uptake system was shown to be fully expressed and may be involved in transport of haemoglobin-derived iron into the cell. Uptake of ovotransferrin-bound iron took place immediately upon exhaustion of haemoglobin-derived iron. The ability to use iron derived from haem compounds represents an alternative iron uptake mechanism for organisms growing in an iron-limited environment and allows greater flexibility during growth in vivo.
\end{abstract}

\section{Introduction}

Enteropathogenic Escherichia coli (EPEC) are a well recognised cause of infantile diarrhoea. ${ }^{1}$ Virulence factors detected in these organisms include the ability to adhere to intestinal epithelium causing elongation and effacement of intestinal microvilli. ${ }^{2,3}$

It is now recognised that pathogenic bacteria have a nutritional need for iron and must obtain it from the environment. To accomplish this, bacteria produce a range of high-affinity iron uptake transport systems, comprising low mol. wt iron chelators ('siderophores') and various proteins involved as membrane receptors for siderophores and for the release of iron from such compounds. ${ }^{4}$

The clinical significance of these high-affinity uptake systems has been demonstrated by showing that many bacteria are iron-restricted during growth in vivo ${ }^{5-7}$ and that growth under such conditions may profoundly alter bacterial properties. ${ }^{5}$ Disruption of iron uptake may be a useful therapeutic strategy; indeed passive immunisation with antibodies against iron-

Received 11 March 1991; accepted 23 Sept. 1991.

* Present address: Department of Microbiology, Hope Hospital, Eccles Old Road, Salford, Manchester M6 8HD. regulated outer-membrane protein (OMPs) has been shown to reduce mortality in an animal septicaemia model. ${ }^{8}$

There is growing evidence that some enteric pathogens are iron-limited in vivo. Vibrio cholerae isolated directly from infected rabbits has been shown to be iron-restricted ${ }^{9}$ and an iron-uptake-deficient Shigella flexneri has a greatly reduced ability to colonise the intestinal tract of rabbits. ${ }^{10}$ Furthermore, we have demonstrated that during the course of EPEC infection in human volunteers, an antibody response can be demonstrated against the iron-regulated outermembrane proteins of the infecting EPEC strain (unpublished observations).

Previous studies have suggested that pathogenic bacteria may have an enhanced ability to obtain iron from the body's iron-binding proteins, compared with avirulent strains. ${ }^{4}$ This may serve as a marker to differentiate EPEC from normal flora $E$. coli strains.

Bacteria living on mucosal surfaces may be able to obtain iron from haem (HM) or haemoglobin (HB) liberated from dying cells on the epithelium; this may alleviate the iron-restriction induced by the ironbinding protein, lactoferrin, present in mucosal secretions. ${ }^{4}$ This may be an important mechanism of iron uptake for bowel pathogens, particularly EPEC, which cause microvillus disruption. 
The purposes of this study were (1) to assess the iron uptake capabilities of EPEC and normal flora $E$. coli strains, (2) to assess the ability of EPEC to utilise different iron-containing compounds during growth in an iron-restricted environment, and (3) to determine possible mechanisms and kinetics of the uptake of iron-containing compounds.

\section{Materials and methods}

\section{Organisms}

The serotypes of 46 EPEC strains used in this study are shown in table I. One EPEC strain was used for further experimentation; this strain E2348/69, kindly provided by $\operatorname{Dr}$ M. M. Levine, Centre for Vaccine Development, Baltimore, has been shown to be virulent in human volunteer studies. ${ }^{11}$ Thirty $E$. coli strains (O serogroup not known, but not belonging to EPEC $O$ serogroups), isolated from the faeces of healthy infants at Freeman Hospital were used as control strains.

\section{Media and reagents}

M9 minimal medium contained $\mathrm{Na}_{2} \mathrm{HPO}_{4} 6 \mathrm{~g}$, $\mathrm{KH}_{2} \mathrm{PO}_{4} 3 \mathrm{~g}, \mathrm{NaCl} 0.5 \mathrm{~g}$ and $\left(\mathrm{NH}_{4}\right)_{2} \mathrm{SO}_{4} 2 \mathrm{~g}$ (all from $\mathrm{BDH}$ ) dissolved in $1 \mathrm{~L}$ of deionised water, adjusted to $\mathrm{pH} \mathrm{7.4}$. The medium was sterilised at $115^{\circ} \mathrm{C}$ for $10 \mathrm{~min}$ and $2 \mathrm{ml}$ of $1 \mathrm{M} \mathrm{MgSO}_{4}, 1 \mathrm{ml}$ of $0.1 \mathrm{M} \mathrm{CaCl}_{2}$ and $10 \mathrm{ml}$ of $20 \%$ glucose (BDH), all sterilised by filtration, were added before cooling.

M9 +ovotransferrin medium (M90) was based on a modification of the medium described by Stevenson

Table I. Serotype and source of EPEC strains

\begin{tabular}{lcccccc}
\hline $\begin{array}{c}\text { EPEC } \\
\text { serotype }\end{array}$ & $\begin{array}{c}\text { Number } \\
\text { of strains }\end{array}$ & & $\begin{array}{c}\text { Number of strains } \\
\text { from each source }\end{array}$ \\
\hline O18ac & 1 & B (1) & & & \\
O26 & 4 & C (1) & D (2) & F (1) & \\
O44 & 4 & B (2) & E (1) & F (1) & \\
O55 & 4 & B (2) & C (1) & E (1) & \\
O86 & 1 & C (1) & & & & \\
O111 & 11 & B (1) & C (4) & E (4) & F (1) & G (1) \\
O114 & 1 & A (1) & & & & \\
O119 & 2 & C (1) & E (1) & & & \\
O125 & 2 & F (2) & & & \\
O126 & 5 & B (1) & E (1) & F (3) & \\
O127 & 2 & A (1) & C (1) & & \\
O128 & 7 & B (2) & C (2) & E (1) & F (2) \\
O142 & 2 & A (1) & B (1) & & \\
\hline
\end{tabular}

A, M. M. Levine, Centre for Vaccine Development, University of Maryland, Baltimore, USA.

B, Department of Microbiology, Royal Victoria Infirmary, Newcastle upon Tyne.

C, D. C. A. Candy, Institute of Child Health, Birmingham.

D, H. W. Smith, Animal Research Centre, Huntingdon.

E, A. Thoren, University of Lund, Malmo, Sweden.

F, Microbiology Department, Freeman Hospital, Newcastle upon Tyne.

G, J. R. Saunders, Department of Microbiology, University of Liverpool. and Griffiths. ${ }^{12}$ Briefly, M9 medium was prepared at $133 \%$ concentration. Iron-free ovotransferrin (Sigma) prepared as described, ${ }^{12}$ and bicarbonate solution, a $0.57 \mathrm{~m}$ solution of $\mathrm{NaHCO}_{3}(\mathrm{BDH})$ in deionised water, were both sterilised by filtration. For use, $125 \mathrm{ml}$ each of ovotransferrin and bicarbonate solutions were added to $750 \mathrm{ml}$ of $\mathrm{M} 9$ medium, giving final concentrations of ovotransferrin $0.5 \mathrm{~g} / \mathrm{L}$ and $0.071 \mathrm{M} \mathrm{bi}$ carbonate. M90 medium was also prepared supplemented with $1 \%$ casamino acids (Difco). Iron-restricted tryptone soy broth $(\mathrm{Fe}-\mathrm{TSB})$ was prepared as described. ${ }^{12}$

The degree of saturation of ovotransferrin in M90 was determined with a MIRAS analyser and was $\approx$ $20 \%$, equivalent to an $\mathrm{Fe}^{3+}$ concentration of $0.14 \mathrm{mg} / \mathrm{L}$. In some cases the medium was made iron replete by the addition of $0.5 \mathrm{ml}$ of $0.1 \% \mathrm{FeCl}_{3}$ to $80 \mathrm{ml}$ of medium.

Haem (HM) and haemoglobin (HB) solutions HM (Sigma) $50 \mathrm{mg}$ was dissolved in $200 \mu \mathrm{l}$ of triethylamine and made up to $100 \mathrm{ml}$ with deionised water. Human HB (Sigma) was dissolved in deionised water to a concentration of $0.5 \mathrm{~g} / \mathrm{L}$. Solutions were sterilised by filtration.

\section{Detection of siderophores}

Enterochelin content of supernates was quantitated $(\mathrm{mg} / \mathrm{L})$ colorimetrically at $515 \mathrm{~nm}$ with the nitritemolybdate reagent of $A$ nnow $^{13}$ and a standard curve of dihydroxy-phenylalanine (Sigma) solution (1$200 \mathrm{mg} / \mathrm{L}$ ). The ability of strains to produce aerobactin was determined by a cross feeding bioassay ${ }^{14}$ with the aerobactin-dependent strain LG1522, (kindly supplied by Dr P. Williams, Department of Genetics, University of Leicester). The presence of aerobactin in culture supernates was detected with the ferric perchlorate test and by bioassay. ${ }^{14}$

\section{Culture conditions}

M90 cultures were inoculated with an overnight culture of the $E$. coli strain grown in Tryptone Soy Broth (TSB) (Difco) to give an initial cell density of $2 \times 10^{6}$ organisms $/ \mathrm{ml}$. Cultures were incubated at $37^{\circ} \mathrm{C}$ in a shaking waterbath at $120 \mathrm{rpm}$ for $24 \mathrm{~h}$ unless specified. $\mathrm{Fe}-\mathrm{TSB}$ cultures were similarly inoculated but with an initial cell density of $5 \times 10^{4}$ organisms $/ \mathrm{ml}$.

\section{Effect of haem (HM) and haemoglobin $(H B)$ on growth $\left(A_{400}\right)$ and enterochelin $(\mathrm{mg} / \mathrm{L})$ production}

The ability of HB or HM to stimulate the growth of EPEC and normal flora strains was examined with $\mathrm{M} 90, \mathrm{M} 90$ - casamino acids and iron restricted TSB containing $\mathrm{HM}$ or $\mathrm{HB}$ to a final concentration of $12.5 \mathrm{mg} / \mathrm{L}$. Media, with and without HB or HM, were inoculated and incubated as described. After incubation, growth was measured by determination of the $\mathrm{A}_{400}$ of the culture. Supernates were collected and the 
enterochelin content was determined. The criterion for growth stimulation by $\mathrm{HB}$ or $\mathrm{HM}$ was greater than a three-fold increase in $A_{400}$ in HM or HB supplemented medium compared with the unsupplemented medium. Aerobactin producing strains (aer $+v e)$, which grew well in media without added HB or HM, were tested after incubation for $8 \mathrm{~h}$; forty-six EPEC strains and 30 control strains were tested for growth stimulation by this method.

Strain E2348/69 was tested at different concentrations of $\mathrm{HB}$ and $\mathrm{HM}$, ranging from 0.6 to $50 \mathrm{mg} / \mathrm{L}$ in M90 medium. The $\mathbf{A}_{400}$ and enterochelin content were measured as previously described.

\section{Influence of haemoglobin on growth rate}

Strain E2348/69 was inoculated into M90 medium, iron-replete M90 and M90 containing HB $3 \cdot 1 \mathrm{mg} / \mathrm{L}$ and $25 \mathrm{mg} / \mathrm{L}$ (final concentrations) and incubated as described. During incubation, cultures were sampled at hourly intervals and the $\mathrm{A}_{\mathbf{4 0 0}}$ was determined.

\section{Uptake of radiolabelled ovotransferrin-bound iron}

Ovotransferrin was labelled with radioactive iron by the addition of $1 \mu \mathrm{Ci}$ of ${ }^{55} \mathrm{Fe}$ citrate (Amersham) to $8 \mathrm{ml}$ of M90. Broths were supplemented with HB (final concentration $25 \mathrm{mg} / \mathrm{L}$ ) and then inoculated with strain E2348/69. The broths were incubated as described; at various time intervals $(8-20 \mathrm{~h})$ the $\mathrm{A}_{400}$ was measured, the culture was centrifuged and the enterochelin content of the supernate determined. The bacterial pellet was washed three times in saline and the radioactivity, due to uptake of ovotransferrinbound iron was measured in a $\gamma$ counter. This experiment was performed on two different occasions and the mean results were calculated.

\section{Influence of $H B$ on outer-membrane protein (OMP) profiles}

Strain E2348/69 was inoculated into $150 \mathrm{ml}$ samples of M90 containing HB (final concentration $25 \mathrm{mg} / \mathrm{L}$ ) and iron-replete $\mathrm{M} 90$ and incubated as described. After incubation for $12 \mathrm{~h}$, one HB-containing culture was centrifuged at $3000 \mathrm{~g}$ for $15 \mathrm{~min}$. From the washed cell pellet, OMPs were prepared after sonication and sarkosyl extraction by the method of Achtman et al..$^{15}$ The remaining flasks were incubated for a further $6 \mathrm{~h}$ and then subjected to the same procedure.

The OMPs were subjected to SDS-PAGE in a $3 \%$ loading gel and a $10 \%$ running gel, and run overnight with a constant current of $10 \mathrm{~mA}$. The gels were then stained with Coomassie Blue as described. ${ }^{16}$ OMPs of strain 1 grown for $6 \mathrm{~h}$ in TSB were also examined for comparison.

\section{Determination of haemolytic activity}

EPEC strains were spot inoculated on to Columbia agar (Lab M) supplemented with either horse or sheep blood (Gibco) $5 \%$. After incubation at $37^{\circ} \mathrm{C}$ for $18 \mathrm{~h}$, plates were examined for zones of haemolysis around the colonies.

\section{Results}

\section{Growth of E. coli strains in iron-restricted media}

Growth of 28 out of 46 EPEC and 19 of 30 control E. coli strains in $\mathrm{M} 90$ and $\mathrm{M} 90+$ casamino acids was poor $\left(A_{400}<0.3\right)$. The remaining strains from both groups that grew well in these media $\left(A_{400}>2.0\right)$ were aer + ve when tested in the bioassay (table II). The incidence of aer + ve strains was similar in both the EPEC $(39 \%)$ and control groups (37\%). Enterochelin yields from aer-ve EPEC and control strains were also similar (table II). Yields of enterochelin from aer + ve strains were higher than those from aer-ve strains but there was no significant difference in enterochelin yields between aer + ve EPEC and aer + ve control strains. The addition of iron to M90 medium enhanced the growth of enterochelin-producing strains $\left(A_{400}>2.0\right)$ and enterochelin could not be detected in culture supernatants (limit of detection $0.4 \mathrm{mg} / \mathrm{L}$ ).

\section{The effect of supplementation with $H M$ and $H B$ on growth and siderophore production}

In strains that produced enterochelin only, stimulation of growth in M90 medium by HM or HB was readily detected, due to the marked increase in growth after incubation for $24 \mathrm{~h}\left(\mathrm{~A}_{400}>2.0\right)$. Some strains were stimulated by both $\mathrm{HB}$ and HM, others were stimulated by HM only. No strains were found which were stimulated by HB but not by HM (table III). Aer + ve strains grew well in M90 after $24 \mathrm{~h}$ without added HB or HM. However, growth stimulation could be detected by both HB and HM in 11 out of 18 aer + ve strains and by HM only in one of 18 aer + ve EPEC strains when the cultures were examined after incubation for $8 \mathrm{~h}$.

With $\mathrm{Fe}-\mathrm{TSB}$ as the culture medium, growth stimulation by both HM and HB could be detected

Table II. Growth $\left(\mathrm{A}_{400}\right)$, enterochelin and aerobactin production by EPEC and control E. coli strains grown in M90 medium

\begin{tabular}{lc|ccc}
\hline & & \multicolumn{3}{|c}{ After growth for 24 h } \\
\cline { 3 - 5 } E. coli & $\begin{array}{c}\text { Number of } \\
\text { strains (\%) }\end{array}$ & $\begin{array}{l}\text { Aerobactin } \\
\text { production }\end{array}$ & $\begin{array}{c}\text { Mean (SD) } \\
\mathrm{A}_{400}\end{array}$ & $\begin{array}{c}\text { Mean (SD) } \\
\text { enterochelin } \\
\text { content (mg/L) }\end{array}$ \\
\cline { 3 - 5 } EPEC & $18(39)$ & + & $2.8(0.5)$ & $\begin{array}{l}5.9(1 \cdot 1) \\
1.9(0.5)\end{array}$ \\
Control & $11(37)$ & + & $\begin{array}{l}0.12(0.03) \\
2.4(0.4)\end{array}$ & $\begin{array}{l}6.1(1 \cdot 2) \\
1.7(0.6)\end{array}$ \\
strains & $19(63)$ & - & $0.11(0.03)$ & \\
\hline
\end{tabular}


Table III. Stimulation of growth of EPEC and control E. coli strains by haem and haemoglobin $(12.5 \mathrm{mg} / \mathrm{L})$ in $\mathrm{M} 90$ medium

\begin{tabular}{l|cc}
\hline & \multicolumn{2}{|c}{$\begin{array}{c}\text { Gumber (\%) } \\
\text { stimulation strains }\end{array}$} \\
\cline { 2 - 3 } & EPEC & $\begin{array}{c}\text { Control } \\
\text { strains }\end{array}$ \\
\hline HM + ve HB-ve & $9(19 \cdot 6)$ & $6(20)$ \\
HM - ve HB + ve & 0 & \\
HM + ve HB +ve & $28(60 \cdot 8)$ & $17(56 \cdot 6)$ \\
HM - ve HB - ve & $9(19 \cdot 6)$ & $7(23 \cdot 3)$ \\
Total & 46 & 30 \\
\hline
\end{tabular}

*Stimulation is denoted by a greater than three-fold increase in $A_{400}$ in supplemented media compared with unsupplemented media.

For aerobactin producing strains, results were determined after incubation for $8 \mathrm{~h}$; for all other strains, results were determined after $24 \mathrm{~h}$.

from low inocula after incubation for $8 \mathrm{~h}$ with strains E2348/69 and 1367/80 (serogroup O111) (table IV).

When the supernates of strains stimulated by $\mathrm{HM}$ or HB were examined, high levels of enterochelin were detected (table IV) and aerobactin was detected in the supernates of aer + ve strains by both bioassay and the ferric perchlorate test (data not shown).

With strain E2348/69, growth $\left(\mathrm{A}_{400}\right)$ and enterochelin production $(\mathrm{mg} / \mathrm{L})$ was found to increase with rising concentrations of both $\mathrm{HB}$ and $\mathrm{HM}$ (table V). In the case of HM, maximal growth and enterochelin yield was achieved at concentrations of $3 \cdot 1-6 \cdot 25 \mathrm{mg} / \mathrm{L}$ after which a slight decrease in both $\mathrm{A}_{400}$ and enterochelin production was seen. Maximal growth was seen with a $\mathrm{HB}$ concentration of $25-50 \mathrm{mg} / \mathrm{L}$ but maximal enterochelin production occurred at a $\mathrm{HB}$ concentration of $6.25 \mathrm{mg} / \mathrm{L}$.

The effect of HB supplementation on the growth rate of strain E2348/69 is clearly demonstrated in fig. 1. HB stimulated the growth rate in a dose dependent manner. However, the growth rate was lower than that of iron-replete M90.
Table IV. Enterochelin production and growth of EPEC strains E2348/69 and 1367/80 (serogroup O111) grown in M90 medium for $24 \mathrm{~h}$ or $\mathrm{Fe}-\mathrm{TSB}$ for $8 \mathrm{~h}$ supplemented with haem or haemoglobin

\begin{tabular}{|c|c|c|c|c|c|}
\hline \multirow[b]{2}{*}{ Strain no. } & \multirow[b]{2}{*}{ Supplement } & \multicolumn{2}{|c|}{ M90 medium } & \multicolumn{2}{|r|}{ Fe-TSB } \\
\hline & & $A_{400}$ & $\begin{array}{c}\text { enterochelin } \\
\mathrm{mg} / \mathrm{L}\end{array}$ & $\mathbf{A}_{400}$ & $\begin{array}{c}\text { enterochelin } \\
\mathrm{mg} / \mathrm{L}\end{array}$ \\
\hline \multirow[t]{3}{*}{ E2348/69 } & None & $0 \cdot 1$ & 0.8 & 0.5 & 0.6 \\
\hline & $\mathrm{HB} 25 \mathrm{mg} / \mathrm{L}$ & 1.8 & $5 \cdot 5$ & 1.7 & 6.9 \\
\hline & $\mathrm{HM} 25 \mathrm{mg} / \mathrm{L}$ & $3 \cdot 0$ & $13 \cdot 0$ & 2.5 & $3 \cdot 1$ \\
\hline \multirow[t]{3}{*}{$1367 / 80$} & None & $0 \cdot 16$ & $1 \cdot 1$ & 0.6 & 0.6 \\
\hline & HB $25 \mathrm{mg} / \mathrm{L}$ & $2 \cdot 3$ & $6 \cdot 1$ & $2 \cdot 7$ & 8.8 \\
\hline & $\mathrm{HM} 25 \mathrm{mg} / \mathrm{L}$ & $3 \cdot 4$ & $13 \cdot 6$ & $2 \cdot 5$ & 5.9 \\
\hline
\end{tabular}

Table $V$. The influence of haem and haemoglobin concentration on growth and enterochelin production by strain E2348/69 in M90 medium

\begin{tabular}{|c|c|c|c|c|}
\hline \multirow{2}{*}{$\begin{array}{c}\text { Concentration } \\
\text { of } \mathrm{HB} \text { or } \mathrm{HM} \\
(\mathrm{mg} / \mathrm{L})\end{array}$} & \multicolumn{2}{|c|}{$\mathrm{M} 90+\mathrm{HB}$} & \multicolumn{2}{|c|}{ M90 + HM } \\
\hline & $A_{400}$ & $\begin{array}{l}\text { enterochelin } \\
\mathrm{mg} / \mathrm{L}\end{array}$ & $\mathbf{A}_{400}$ & $\begin{array}{c}\text { enterochelin } \\
\mathrm{mg} / \mathrm{L}\end{array}$ \\
\hline 0.6 & 0.5 & $1 \cdot 5$ & 0.44 & 1.75 \\
\hline $1 \cdot 25$ & 0.96 & $3 \cdot 0$ & $1 \cdot 1$ & 2.9 \\
\hline $3 \cdot 12$ & $1 \cdot 3$ & 3.9 & $3 \cdot 2$ & $15 \cdot 3$ \\
\hline 6.25 & $2 \cdot 25$ & 6.2 & $4 \cdot 5$ & 14.5 \\
\hline $12 \cdot 5$ & $2 \cdot 5$ & 5.9 & 3.9 & $9 \cdot 2$ \\
\hline 25 & 2.9 & $5 \cdot 8$ & 3.7 & 6.9 \\
\hline 50 & $2 \cdot 9$ & 3.7 & ND & ND \\
\hline
\end{tabular}

ND, not done.

$\mathrm{A}_{400}$ and enterochelin content were determined after incubation for $24 \mathrm{~h}$.

\section{Uptake of radiolabelled ovotransferrin-bound iron}

The results of the uptake study are shown in fig. 2. As strain E2348/69 grew it did not take up the ovotransferrin-bound radioactive iron for $16 \mathrm{~h}$. During this time, enterochelin was detected in increasing

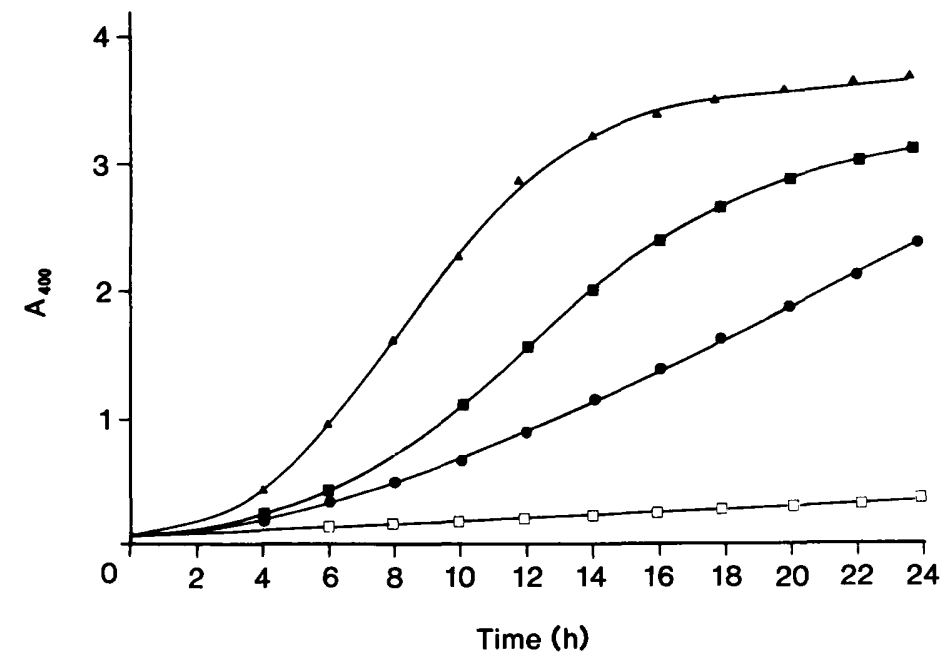

Fig. 1. Growth of EPEC strain E2348/69 in $\mathrm{M} 90$ medium containing $\mathrm{FeCl}_{3}$ or haemoglobin : $\mathbf{\Delta}-\mathbf{A}, \mathbf{M} 90+\mathrm{FeCl}$; $25 \mathrm{mg} / \mathrm{L} ; \bigcirc-\mathrm{O}, \mathrm{M} 90+\mathrm{HB} 3 \cdot 1 \mathrm{mg} / \mathrm{L} ; \square-\square, \mathrm{M} 90$. 


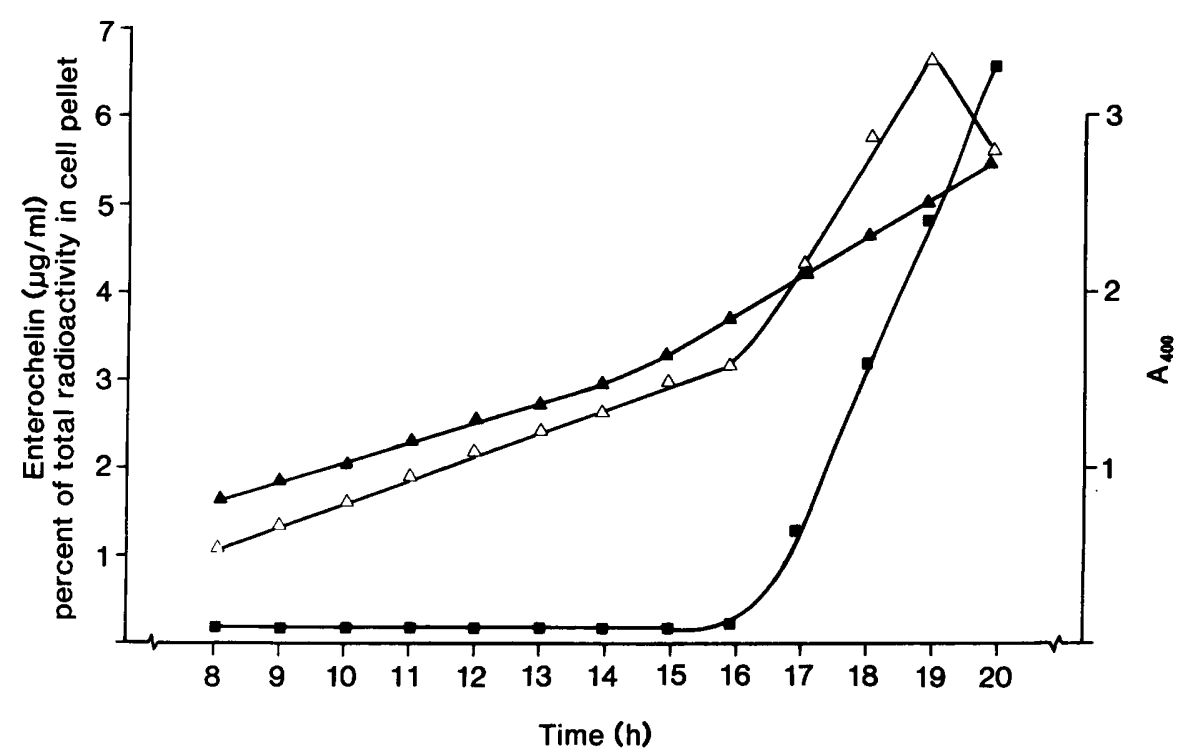

Fig. 2. Growth $\left(A_{400}\right)$, enterochelin content and iron uptake of EPEC strain E2348/69 in M90 medium containing HB $25 \mathrm{mg} / \mathrm{L}$ (mean of two determinations) : $\Delta \longrightarrow \Delta, \mathrm{A}_{400} \triangle \longrightarrow \triangle$, enterochelin content of supernate $(\mathrm{mg} / \mathrm{L}) ; \square-\mathbf{D}$, percentage of radiolabelled iron in cell pellet.

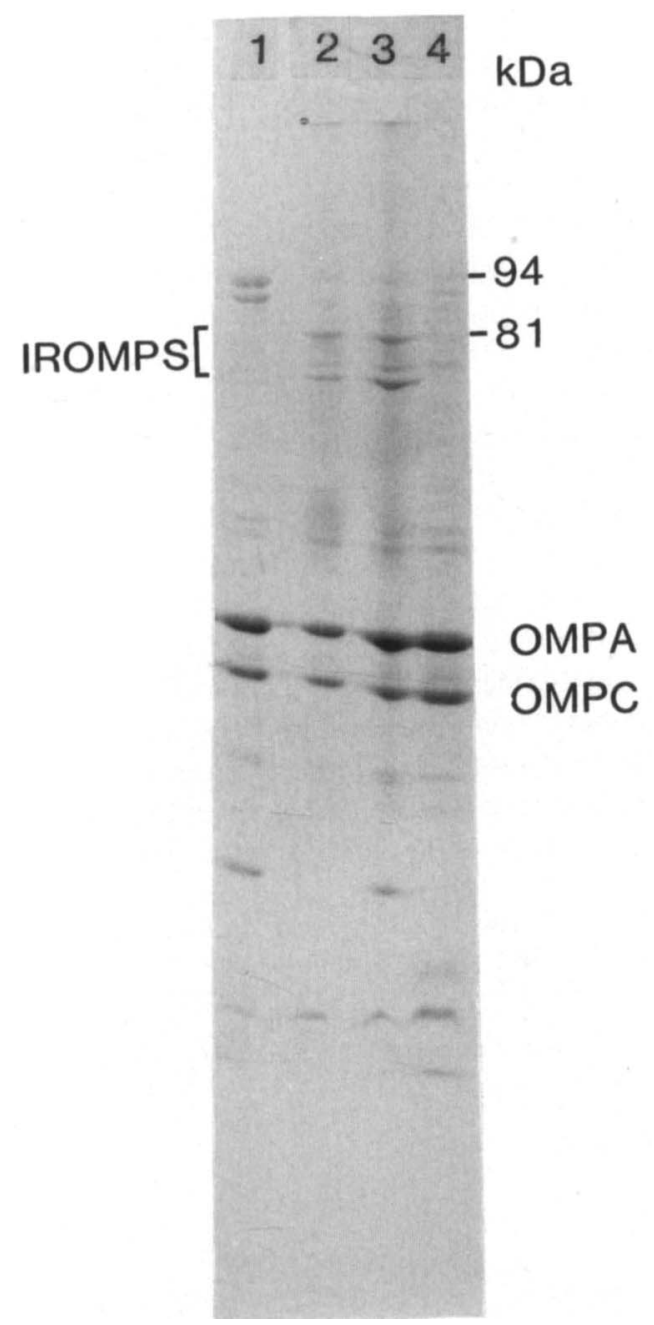

Fig. 3. SDS-PAGE of outer membranes of EPEC strain E2348/69 grown under different conditions: Lane 1 , tryptone soy broth, $6 \mathrm{~h}$; 2, M90 + HB $25 \mathrm{mg} / \mathrm{L}, 12 \mathrm{~h} ; 3, \mathrm{M} 90+\mathrm{HB} 25 \mathrm{mg} / \mathrm{L}, 18 \mathrm{~h} ; 4$, ironreplete M90, $18 \mathrm{~h}$; IROMPS, iron regulated outer-membrane proteins; OMPA, outer-membrane protein A; OMPC, outermembrane protein C. (Loading, c. $30 \mu \mathrm{g}$ of protein/lane.) quantities in the culture supernate. After $16 \mathrm{~h}$, there was a dramatic increase in the uptake of radioactive iron obtained from the ovotransferrin. There was also a corresponding increase in enterochelin production and a slight increase in growth rate (fig. 2).

Outer-membrane protein production during iron $(H B)$ stimulated growth

OMPs of strain E2348/69 grown under HBstimulated conditions for $12 \mathrm{~h}$ and examined by SDSPAGE clearly demonstrated the presence of ironregulated OMPs (IROMP) (fig. 3, lane 2). The OMP profile of these organisms resembled those of the same strain grown under identical conditions for $18 \mathrm{~h}$ (fig. 3, lane 3) at which time the HB is exhausted and ovotransferrin-bound iron is used as the iron source. Growth of organisms in iron-replete M90 shows repression of the IROMPs (fig. 3, lane 4).

\section{Examination of strains for haemolysis}

When examined for haemolysis on both horse and sheep blood agar, only two EPEC strains were found to be haemolytic.

\section{Discussion}

The iron-uptake systems of EPEC strains and normal flora non-EPEC control strains were compared. The incidence of aerobactin production was similar. The yields of enterochelin from aer - ve EPEC and control strains were similar, as were the yields from aer + ve EPEC and control strains. All of the strains that produced enterochelin alone grew poorly in the M90 medium even when supplemented with 
casamino acids, whereas aer + ve strains grew well, showing that there was sufficient iron available, bound to the ovotransferrin. The superiority of aerobactin as a growth stimulator could not be explained by protein binding or antibody interference with enterochelin uptake. Enterochelin is secreted at a much later stage of growth than aerobactin ${ }^{17}$ and, in $E$. coli strains, transferrin preferentially induces the aerobactin uptake system. ${ }^{18}$ These effects may account for the better growth of aerobactin-producing strains in this study.

Iron-containing compounds derived from dead, sloughed epithelial cells may provide bacteria with essential iron during growth on mucosal surfaces. ${ }^{4}$ Enteric pathogens may be able to utilise these compounds whilst growing in an iron-limited environment. $V$. cholerae strains are able to utilise $\mathrm{HM}$ and $\mathrm{HB}$ as iron sources. ${ }^{19}$ Similarly, S. flexneri has been shown to utilise haemin as an iron source. ${ }^{20}$ In this study, $61 \%$ and $80 \%$ of EPEC were able to utilise HB and HM, respectively as iron sources during growth in an ironlimited environment. Interestingly, only two EPEC strains were haemolytic, supporting previous findings, ${ }^{21}$ whereas the $V$. cholerae strains described previously ${ }^{19}$ were haemolytic. Griffiths ${ }^{4}$ suggested that for an organism to utilise $\mathrm{HM}$ or $\mathrm{HB}$ it would be necessary for these to first be released from host cells by the action of haemolysins. The absence of haemolysins from the majority of EPEC strains suggests that free iron-containing groups may exist in the intestinal environment which can be used by bacteria. Conclusive evidence of the presence of these groups in the intestinal tract is lacking. However, during a case of protracted diarrhoea caused by an EPEC strain, although the faeces did not appear bloody, occult blood could be detected. ${ }^{22}$

The use of HB- or HM-derived iron is an alternative mechanism of iron uptake for bacteria growing in an iron-limited environment and allows bacteria to overcome the growth-retarding effects of lactoferrin.

Removal of iron directly from HM and HB by enterochelin appears unlikely, because strains unable to use $\mathrm{HB}$ or $\mathrm{HM}$ iron produced quantities of enterochelin similar to those produced by strains able to use these groups as iron sources when grown in unsupplemented media. However, enterochelin and aerobactin, in conjunction with the IROMPs, may serve to transport HM- or HB-derived iron into the cell after its release from these molecules. When EPEC strain E2348/69 was grown with two sources of available iron (HB and ovotransferrin), despite the production of both IROMPs and enterochelin, ovotransferrin-bound iron was not taken up into the bacterial cells for $16 \mathrm{~h}$. During this time, HB acted as the source of iron; after exhaustion of this iron supply, the siderophores remove ovotransferrin-bound iron which is taken into the cell. The growth rate of an EPEC strain with $\mathrm{HB}$ as an iron source was related directly to the HB concentration and was much higher than the same strain growing in the same medium without $\mathrm{HB}$.

It is not clear why high concentrations of HM cause a decrease in both growth and enterochelin production. It is possible that: (1) HM or its degradation products are toxic, reducing growth and enterochelin synthesis; (2) HM or its degradation products inhibit enterochelin synthetic pathways, with growth being reduced due to impaired iron transport; or (3) the quantity of HM-derived iron brought into the cell, especially at high HM concentrations, may cause repression of the enterochelin system, resulting in reduced growth due to impaired enterochelinmediated iron transport.

In some bacteria, e.g. Bacteroides fragilis and Haemophilus influenzae, OMPs of $43-44 \mathrm{kDa}$ are involved in the uptake of $\mathrm{HM}{ }^{23} \mathrm{~A}$ role for OMPs in the uptake of HM by EPEC strains cannot be excluded; however, OMPs of EPEC strain E2348/69 growing with HB-derived or ovotransferrin-derived iron appeared identical.

HB- and HM-mediated growth stimulation is not restricted to pathogenic strains of $E$. coli such as EPEC, but is present in similar numbers of control $E$. coli strains. Colonisation of the bowel may be favoured by the ability of $E$. coli strains to use these compounds. Chart et al. ${ }^{24}$ showed that EPEC strains and normal flora $E$. coli strains had similar IROMP profiles, which differed from those of $E$. coli isolates from extraintestinal sites. Thus, the iron uptake mechanisms of EPEC and normal bowel $E$. coli strains may be suited to the intestinal environment and to exploitation of locally available iron sources, whereas extra-intestinal strains have iron uptake systems suitable for existence at other body sites. It will be of interest to investigate the incidence of HB and HM utilisation of such isolates and also other enteric pathogens.

We thank Newcastle Area Health Authority for financial assistance; M. Kehoe and the staff in the Pathogenicity Laboratory, Newcastle University, for assistance with outer-membrane preparations and SDS-PAGE; T. Hawkins for supplying the radioisotopes; the microbiologists who generously supplied the organisms; the Biochemistry Department at Freeman Hospital for transferrin saturation measurements; and G. Megson for assistance with the illustrations.

\section{References}

1. Levine MM, Edelman R. Enteropathogenic Escherichia coli of classic serotypes associated with infant diarrhea; epidemiology and pathogenesis. Epidemiol Rev 1984; 6: 31-51.

2. Levine MM. Escherichia coli that cause diarrhea: Enterotoxigenic, enteropathogenic, enteroinvasive, enterohem- morrhagic, and enteroadherent. $J$ Infect Dis 1987; 155: 377-389.

3. Law D. Virulence factors of enteropathogenic Escherichia coli. J Med Microbiol 1988; 26: 1-10.

4. Griffiths $E$. The iron-uptake systems of pathogenic bacteria. In Bullen JJ, Griffiths E (eds) Iron and infection. Chichester, John Wiley. 1985: 69-137.

5. Brown MRW, Williams P. The influence of environment on 
envelope properties affecting survival of bacteria in infection. Annu Rev Microbiol 1985; 39: 527-556.

6. Ward KH, Anwar H, Brown MRW, Wale J, Gowar J. Antibody response to outer-membrane antigens of Pseudomonas aeruginosa in human burn wound infection. J Med Microbiol 1988; 27 : 179-190.

7. Shand GH, Anwar H, Kadurugamuwa J, Brown MRW, Silverman SH, Melling J. In vivo evidence that bacteria in urinary tract infection grow under iron-restricted conditions. Infect Immun 1985; 48: 35-39.

8. Bolin CA, Jensen AE. Passive immunization with antibodies against iron-regulated outer membrane proteins protects turkeys from Escherichia coli septicaemia. Infect Immun 1987; 55: 1239-1242.

9. Sciortino CV, Finkelstein RA. Vibrio cholerae expresses ironregulated outer membrane proteins in vivo. Infect Immun 1983; 42: 990-996.

10. Nassif X, Mazert M-C, Mounier J, Sansonetti PJ. Evaluation with an iuc::Tn 10 mutant of the role of aerobactin production in the virulence of Shigella flexneri. Infect Immun 1987; 55: 1963-1969.

11. Levine MM, Nataro JP, Karch $\mathrm{H}$ et al. The diarrheal response of humans to some classic serotypes of enteropathogenic Escherichia coli is dependent on a plasmid encoding an enteroadhesiveness factor. $J$ Infect Dis 1985; 152: 550-559.

12. Stevenson P, Griffiths E. Growth of Escherichia coli under ironrestricted conditions. In: Sussman M (ed) The virulence of Escherichia coli. (Special publication of the Society for General Microbiology 13.) London, Academic Press. 1985: 413-417.

13. Arnow LE. Colorometric determination of the components of 3, 4-dihydroxyphenylalanine-tyrosine mixtures. $J$ Biol Chem 1937; 11: 531-537.

14. Carbonetti NH, Williams PH. Detection of synthesis of the hydroxamate siderophore aerobactin by pathogenic isolates of Escherichia coli. In: Sussman M (ed) The virulence of Escherichia coli. (Special publication of the Society for General Microbiology 13.) London, Academic Press. 1985: 419-424.
15. Achtman M, Mercer A, Kusecek B et al. Six widespread bacterial clones among Escherichia coli $\mathrm{K} 1$ isolates. Infect Immun 1983; 39: 315-335.

16. Stevenson $P$, Griffiths $E$. Detection of antibodies and antigens by immunoblotting. In: Sussman $M$ (ed) The virulence of Escherichia coli. (Special publication of the Society for General Microbiology 13.) London, Academic Press. 1985: 457-463.

17. Der Vartanian M. Differences in excretion and efficiency of the aerobactin and enterochelin siderophores in a bovine pathogenic strain of Escherichia coli. Infect Immun 1988; 56: 413-418.

18. Williams PH, Carbonetti NH. Iron, siderophores, and the pursuit of virulence: independence of the aerobactin and enterochelin iron uptake systems in Escherichia coli. Infect Immun 1986; 51 : 942-947.

19. Stoebner JA, Payne SM. Iron-regulated hemolysin production and utilization of heme and hemoglobin by Vibrio cholerae. Infect Immun 1988; 56: 2891-2895.

20. Lawlor KM, Daskaleros PA, Robinson RE, Payne SM. Virulence of iron transport mutants of Shigella flexneri and utilization of host iron compounds. Infect Immun 1987; 55: 594-599.

21. Buetin L, Montenegro M, Zimmermann S, Stephan R. Characterization of hemolytic strains of Escherichia coli belonging to classical enteropathogenic O-serogroups. Zentralbl Bakteriol Mikrobiol Hyg A 1986; 261 : 266-279.

22. Ulshen MH, Rollo JL. Pathogenesis of Escherichia coli gastroenteritis in man-another mechanism. $N$ Engl $J$ Med $1980 ; 302$ : $99-101$.

23. Otto BR, Sparrius M, Verweij-van Vught AMJJ, MacLaren DM. Iron-regulated outer membrane protein of Bacteroides fragilis involved in heme uptake. Infect Immun 1990; 58: 3954-3958.

24. Chart H, Stevenson P, Griffiths E. Iron-regulated outermembrane proteins of Escherichia coli strains associated with enteric or extraintestinal diseases of man and animals. J Gen Microbiol 1988; 134: 1549-1559. 